\title{
An Evaluation of the Growth and Water Consumption Rate of Grain Sorghum (Sorghum bicolor) at Four Climatic Sites in the Tropics and Subtropics, ${ }^{1,2}$
}

\author{
Modesto Capiel, Eduardo Brenes, M. A. Lugo-López, Paul G. Schoch, \\ and Victor L. Guzmán ${ }^{3}$
}

\begin{abstract}
An ecologic study was conducted to evaluate the dry matter yield response and the mean daily growth and water consumption rates of grain sorghum at four climatic sites in the tropics and subtropics. BR-54 seeds of this crop were grown in pots watered by capillarity with a specially-devised fiberglass wick-tin can reservoir technique which permitted water use measurements and drainage through the same wick. Seven weekly harvests were made of shoots and roots separately over a 52-day growth period centered on the March 22 vernal equinox.

Climatic sites had a marked effect on dry matter yields (weight of the shoot). The yield response is directly related to the amount of water consumed which, at the same time, is closely related to the leaf area. However, an analysis of variance indicates that the relative growth rate, unit leaf area, water use rate, and other related indices did not significantly differ with climatic sites. As a result, it was found that there existed highly significant quadratic relationships of the relative growth rates and water use rates as a function of days after emergence when the four climatic sites were included together in regression analysis.

Linear regression analysis showed also a significant relationship of unit leaf rate and water use rate on the mean daily values of solar radiation intensity and, to a lesser extent, to the open-pan evaporation.
\end{abstract}

\section{INTRODUCTION}

This climatic study with grain sorghum was planned to look for a broader appraisal of the transferability of technological information

${ }^{1}$ Manuscript submitted to Editorial Board May 2, 1977.

${ }^{2}$ This study was performed while the senior author was on Sabbatic leave during part of 1974 and 1975. It is a joint contribution from the Department of Agronomy, Cornell University, Ithaca, N.Y., and the Agricultural Experiment Station, University of Puerto Rico, Mayagüez Campus, Río Piedras, P.R., with the cooperation of the Station of Bioclimatology, INRA, Domaine Duclos, Petit Bourg, Guadeloupe and the Agricultural Research and Education Center, University of Florida, Belle Glade, Fla. This study was part of the work supported by USAID under research contract ta-c-1104 entitled "Soil Fertility in the Humid Tropics."

${ }^{3}$ Former Agricultural Climatologist, former Associate Soil Scientist, former Professor and Soil Scientist (now Consultant, Cornell University), Agricultural Experiment Station, University of Puerto Rico, Mayagüez Campus, Río Piedras, P.R., Director, Station of Bioclimatology, INRA, Domaine Duclos, Petit Bourg, Guadeloupe, and Professor (Horticulturist), Agricultural Research and Education Center, University of Florida, Belle Glade, Fla., respectively. Appreciation is expressed to the technical staff of the Statistics Section for their suggestions. The valuable suggestions on the revision of this manuscript, given by Dr. Alex G. Alexander, from the Department of Agronomy and Soils, are also appreciated. 
from the so-called "benchmark soils" to their counterparts in problem areas with inadequate scientific information to maximize their crop yields. Such know-how may find greater support when viewed within the context of the soil-plant-air panorama.

It is well known that the root-zone soil and the leaf-space atmosphere, together, make up the essential media upon which plants depend for crop production. Yet, in referring to benchmark soils (2) only the solid part of the system is characterized. The role of the atmosphere in contributing to the water and mineral flux into plants is often taken for granted.

However, the environmental factors which influence transpiration and stomatal aperture exert an invariable, significant control on the internal water status of the plants and in their Hill reaction. Thus, if the soil water is depleted by the plants without adequate replenishment by either rainfall or irrigation, it becomes difficult to determine the integrated effect of environmental factors in plant growth and dry matter accumulation.

Soil moisture is an essential ingredient of the soil-plant-air system. An understanding of its contribution to crop production is essential for the correct interpretation of crop data. It should permit a more valid interpretation of the involvement of environmental factors on growth and development of the crop being studied.

\section{PREVIOUS WORK AND PRESENT OUTLOOK}

Some progress has been made in the study of crop-weather relationships relative to soil moisture regimes. New climatic indices have been summarized by Baier (1) in the context of crop-weather analytical models. On the other hand, Paltridge and De Vries (7) concluded, from studies on water-silicon and yield-silicon relationships in wheat, that specific parameter ratios can be used to predict yield potentials for discrete regions.

These authors also conclude that, in view of the climatic summation nature of crop transpiration, other relationships may be developed with this type of data.

In Kansas, Jacques et al. (6) recognized the influence of temperature and rainfall on the growth and mineral content of grain sorghum. sampled at various stages of growth.

However, in tropical latitudes, where air humidity replaces to a large measure air temperature in establishing ecological growth regimes, limited work has been done in evaluating crop yields in light of the plant-water-climate interrelationships. On the rather humid Gurabo Experimental Farm in east-central Puerto Rico an investigation was made on the effect of various meteorological indices on the yield and nutrient composition of irrigated vs. nonirrigated napiergrass, 
under two harvest-frequency regimes and two nitrogen-application rates (3). For the more frequently harvested grass (45-day interval) significant inverse correlations were reported between yields and nutrient composition, and between the latter and certain weather indices. As would be expected, the correlations between yields and weather were positive. In the case of evaporative demands, weather indices such as solar radiation, pan evaporation, and potential evapotranspiration, significant correlations were obtained only with the irrigated forage yields, and in particular with frequently-harvested forage.

It was also found that the use of more than one weather index in multiple-regression analyses appeared to offer significant improvement in the prediction of forage yields. In this case the mean minimum and maximum air temperature, together with the mean solar radiation between harvests, accounted for $97 \%$ of the fluctuations in yields of irrigated forage, harvested every 60 days and fertilized with the lower nitrogen application rate. When both harvest regimes were calculated jointly by monthly yields (19 yields), it was found that the inclusion of a harvest factor in multiple regression further improved the accuracy of forage-yield prediction over that attained with air temperature and solar-radiation indices. In the interaction between certain weather variables and available moisture (from rainfall and irrigation), management interacts with both factors to determine yields under a given set of conditions.

However, not all crops respond equally to weather in spite of the optimal environmental response that readily-available water may impart to the crop. The stage of growth of the crop itself is another plantrelated factor. In a greenhouse study at the Gurabo Experimental farm, Capiel (5) observed that until flowering, bean plants maintained a 1:1 relationship between transpiration and net solar radiation $(r=$ .97) so long as soil moisture was adequate. After bloom initiation, this relationship no longer held, transpiration declining to roughly $40 \%$ of the net radiation. On the other hand, it was found during this same study that the transpiration rate of young coffee plants was always much lower than the net radiation, in addition to being poorly related to it. However, the transpiration of these plants was more sensitive to the air saturation deficit than to any other weather index. Therefore, in general, we can visualize a differential response to weather by plants, confounded many times with the stage of growth but always reflected in the water economy of the plant.

It is concluded that soil-water availability should be taken into account, both with reference to crop physiology and crop management decisions. 


\section{EXPERIMENTAL METHODS AND PROCEDURES}

From November 1974 until seeding in late February 1975, fumigated Coto clay contained in $4 \mathrm{~kg}$ pots was submitted to 12 wetting and drying cycles at four experimental sites. They included: Río Piedras and Isabela, Puerto Rico; Petit Bourg, Guadeloupe; and Belle Glade, Florida. To insure thorough and uniform watering of the potted soil a fiberglass wick $1.3 \mathrm{~cm}$ in diameter and $22 \mathrm{~cm}$ long was inserted through the bottom center of the pots. There were 36 such pots at each site. About $10 \mathrm{~cm}$ of the wick extended vertically into a no. 10 tin can, which served both as water reservoir and support. Accordingly, the conically-shaped pots were inserted as far as they could fit inside the cans, about $5.7 \mathrm{~cm}$ from the can top. To insure atmospheric pressure above the water surface in the tin cans, and at the same time to prevent contact between the bottom of the pots and the water surface, four equidistant $0.3-\mathrm{cm}$ holes were drilled in the can walls at $6.2 \mathrm{~cm}$ from their top, thus leaving a clearance of about $0.5 \mathrm{~cm}$ between the bottom of the plastic pots and the uppermost surface of the water reservoir. This technique served two purposes: a) provision of capillary movement of water to the potted soil above, and b) provision of an adequate efflux via the wick and drainage holes in the event of excess rainfall see (fig. 1).

However, during the wetting and drying cycles before seeding, the cans were emptied during the drying phase for the necessary number of days. Although the experimental soil forms aggregates without difficulty, the 12 wetting and drying cycles during nearly four months promoted uniform aggregation between pots and among locations.

To minimize the differential photoperiodic effects on grain sorghum development as a result of latitudinal differences in daylength, the experimental growth period of 52-55 days was distributed so that the midtime corresponded with the vernal equinox (March 22). This arrangement provided for the least possible standard deviation from a mean of 12 daylight hours, quite similar for any one site or all locations together. In fact, the total daylight hours for 52 days is equal at the four sites $-626.4 \mathrm{~h}$.

A varietal screening for seedling emergence and performance during 2 weeks was made at the four sites, using certified seed of the grain sorghum varieties E-57, BR-54, and BR-63. Each variety showed good germination and initial growth, but BR-54 was finally selected on the basis of percentage germination and uniformity of seedling growth.

Immediately prior to seeding, fertilizer was administered to each container of soil at rates of $300,300,200$, and $50 \mathrm{p} / \mathrm{m}$ of $\mathrm{N}, \mathrm{P}, \mathrm{K}$, and $\mathrm{Mg}$, respectively. In addition, two weeks after seeding, $0.5 \mathrm{p} / \mathrm{m}$ of $\mathrm{Cu}$, 
$\mathrm{Zn}$, and $\mathrm{Mn}$ each, and $2.5 \mathrm{p} / \mathrm{m}$ of $\mathrm{B}$ were added to each pot in $10 \mathrm{ml}$ of aqueous solution, as well as $5 \mathrm{p} / \mathrm{m}$ of $\mathrm{Fe}$ applied separately in $10 \mathrm{ml}$ of solution.

Variety BR-54 was seeded at each site on February 20. The 36 containers at each site were arranged in incomplete randomized blocks with four replications consisting of four rows on $27-\mathrm{cm}$ centers and nine containers per row (replication). Six uniform seeds were placed in each

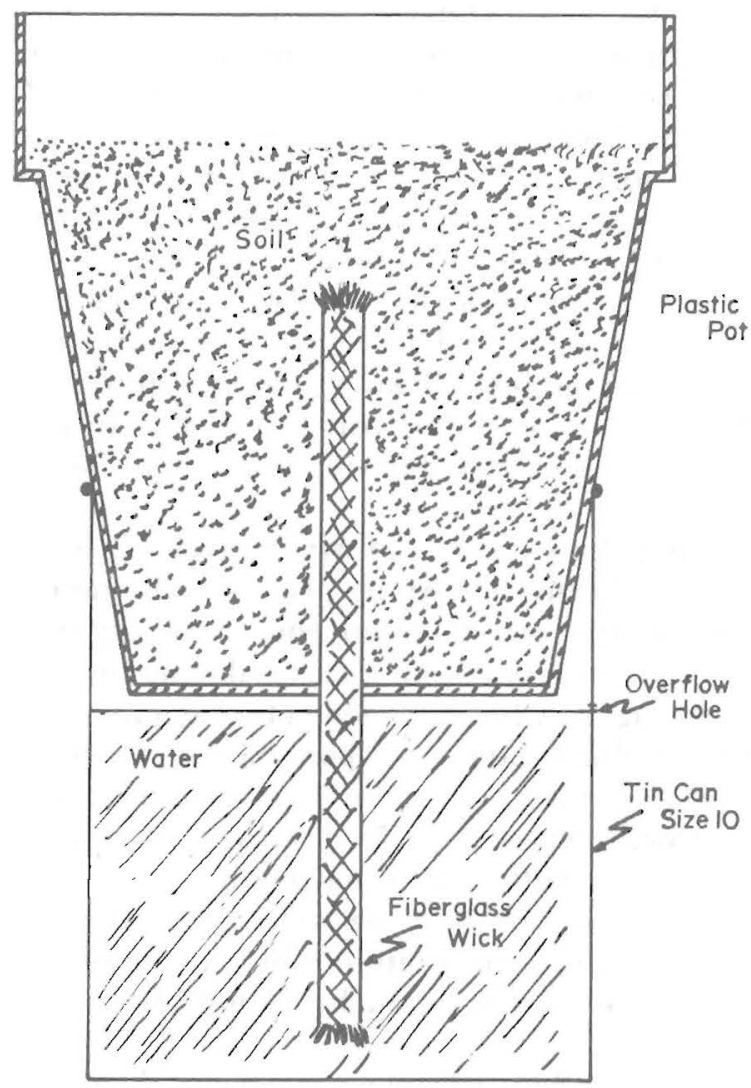

Fig. 1. - System used to insure thorough and uniform watering of the potted soil.

pot at a depth of about $1 \mathrm{~cm}$ equally spaced in a circle conforming with the container surface. Two additional seeds were placed near the center. Seedling emergence data were recorded at five days, except at Belle Glade where emergence required an additional three days.

On the day of seedling emergence each can was filled with water to the level of the four holes. This facilitated the subsequent recording of water consumption. This system proved to be an efficient watering 
technique, in the sense that it seemed to satisfy the plants' water consumption requirements. Even the soil surface was never fully desiccated. The water reservoir capacity in the cans (to the level of the holes) has $2080 \mathrm{ml}$, nearly all of which could be reached by the wick to supply this water to the soil above. However, with depletion of the water reservoir, the rate of capillary rise decreased independently of soil attraction or of evaporative demands. Moisture-removal rates of around $1000 \mathrm{ml} /$ day were observed prior to the last harvest. In these instances water additions to the reservoirs were made almost daily.

Twenty-eight containers were selected for the experiment, after thinning each pot to four uniform plants on the tenth day after emergence. The remaining pots were used as borders. The 28 uniform containers were randomized among and within replications. Within each replicate, seven containers were assigned the harvest numbers 1 to 7 and again randomized.

Beginning with the first harvest 10 days after germination (13 days at Isabela and Petit Bourg), the shoot of each plant was severed at the soil surface. One container per treatment per site was harvested for each of the four replications at weekly intervals. Total leaf area per plant was also measured by making an outline of the opened leaf blades on paper, and calculating the area by planimeter. From the second harvest onward (the third at Belle Glade) three representative leaves from one replicate were retained for blade-area and dry-weight determinations, separately from that of the rest of the leaves at a given harvest. Then, by multiplying the ratio of sample leaf area to sample leaf weight, by the dry weight of the rest of the leaves, the total leaf area was estimated after adding to this value the sample leaf area. Leaf area expanded so rapidly between harvests that it became too time consuming to measure them all before the blades curled. At Petit Bourg the leaf area was determined by an optical planimeter technique.

For the first and second harvests, four plants were sampled per container. After the second harvest, the 28 remaining containers (including the 8 border pots) were thinned out to three plants per pot, to two plants after harvest 3 , and to one plant per pot after harvest 4 . Thus, for the fifth, sixth, and seventh harvests, only one plant was removed from each of the replicates.

In addition to the above-soil material, roots were also harvested and their dry weights determined separately. To approximate the correct dry weight of roots per pot, so that this weight would correspond with the number of plants removed per pot for their dry weight determination, the following calculations were performed:

Third harvest

Correct dry weight of roots per pot, $C D W_{3}=$ dry weight of roots per pot, $D W_{3}-$ (total dry weight of roots on 2 nd harvest $T D W_{2} / 16$ ) 
Fourth harvest

$$
C D W_{4}=D W_{4}-\left(T D W_{3} / 12\right)
$$

Fifth harvest

$$
C D W_{5}=D W_{5}-\left(T D W_{4} / 8\right)
$$

Sixth and Seventh harvests

$$
\begin{aligned}
& C D W_{6}=D W_{6}-\left(T D W_{5} / 4\right) \\
& C D W_{7}=D W_{7}-\left(T D W_{6} / 4\right)
\end{aligned}
$$

Chemical analyses for $\mathrm{N}, \mathrm{P}$, and $\mathrm{K}$ were performed individually for shoot and root tissues.

The water added to the level of the holes between harvests was adjusted for rainfall by adding the product of the $\mathrm{cm}$ of rainfall by the area of the top of the pots $\left(314 \mathrm{~cm}^{2}\right)$ to the $\mathrm{ml}$ of water added on the same time interval. If the estimated volume from rainfall exceeded an estimated amount used for 2 days, the latter figure was then used as the correction. For only the first harvest computation of water consumption was this the case for Río Piedras, Isabela, and Belle Glade. There were no measurements of water added between harvests at Petit Bourg other than adding water to the containers as needed. However, in order to have comparable values of water use $\left(E_{t a}\right)$ between harvests at this site, it was estimated from the average of two simple linear equations of data obtained at Río Piedras and Isabela, the two sites which most nearly resemble the climate of Petit Bourg. One of the equations was obtained by comparing the mean daily water used between weekly harvests against the growth coefficient for the corresponding period $\left(d W_{s} / W_{s}\right.$ at end of period). The other equation was obtained from the weekly water consumed vs. final weight of the plant (shoot plus roots) at the end of each corresponding period. Both linear equations had correlation coefficients of .87 and .96 , respectively, both significant at the $1 \%$ level.

On the other hand, for the last four harvests at Belle Glade, and the second harvest at Petit Bourg, the leaf area had to be estimated from the quadratic relationshp of leaf area as a function of the weight of the plant. It was calculated from all the available data of the four sites, and the correlation coefficient for this quadratic relationship was .97, significant at the $1 \%$ level. The relationship between leaf area $(L a)$ and the weight of the plant was very close, but even closer was that of $L_{a}$ vs $W_{s}$ (shoot weight). However, it was decided to estimate the leaf area for the last four harvests at Belle Glade and the second harvest at Petit Bourg from a plant variable that will not be employed later in the analysis.

Nine growth- and water-use rate indices were used to evaluate the dry-matter accumulation or assimilation rate of grain sorghum among the four locations. In these instances only environmental factors, 
mainly climatic in nature, contributed the essential difference that may be attributed to latitudinal locations.

Some of the growth rate indices discussed are found in the literature (6). The exponential growth rate model

$$
A=B e^{k t},
$$

where $A$ represents a final value of a plant variable attained during a time interval $t, B$ is the value of the same or an associated variable at $t=0$, and $k$ is the slope in question. The plant variables used were weight of shoot $(W s)$, leaf area $(L a)$, and the amount of water used or transpired (Eta). The calculated growth- and water-use-rate indices include relative growth rate (RGR), unit leaf rate (ULR), relative leaf growth rate (RLGR), leaf growth rate (LGR), water use rate (WUR), relative transpiration rate (RT'R), leaf area ratio (LAR), water use efficiency (WUE), and the leaf transpiration efficiency (LTE).

Various climatic variables were recorded and averaged at the four sites, in order to evaluate possible differences in the dry matter accumulation in view of these weather indices. The weather variables averaged for the weekly periods between harvests include solar radiation, air temperature (mean, maximum, and minimum), wind speed, air-saturation deficit, and the dew-point temperature. Values for openpan evaporation were also calculated.

The previously-mentioned growth- and water-use-rate parameters, derived from the indicated exponential growth equation model, were calculated as follows:

1. $W s_{1}=W s_{o} C_{s s} e^{k} s s^{t}$

2. $W s_{1}=L a_{0} C_{s l} e^{k_{s} l^{t}}$

3. $L a_{1}=L a_{o} C_{l l} e^{k l l l^{t}}$

4. $L a_{1}=W s_{o} C_{l s} e^{k} l s^{t}$

5. $E t a_{1}=W s_{0} C_{e s} e^{k_{e S} t}$

6. $E t a_{1}=L a_{0} C_{e l} e^{k_{e} l^{t}}$

7. $L a_{1} / W s_{1}=C_{t s} / C_{s s} e\left(k_{l s}-k_{s s}\right) t$

8. $E t a_{1} / W s_{1}=C_{e s} / C_{s s} e\left(k_{e s}-k_{s s}\right) t$

9. $E t a_{1} / L a_{1}=C_{e l} C_{l l e}\left(k_{e l}-k_{W}\right) t$ where $k_{s s}=\mathrm{RGR}$ where $k_{s l}=$ ULR where $k_{l l}=$ RLGR where $k_{l s}=\mathrm{LGR}$ where $k_{e s}=$ WUR where $k_{e l}=\mathrm{RTR}$ where LAR $=k_{l s}-k_{s s}$ where $\mathrm{WUE}=k_{e s}-k_{s s}$ where $\mathrm{LTE}=k_{e l}-k_{l l}$

As it may be noted, the last three equations-7, 8, and 9-are obtained by dividing equations 4 by 1,5 by 1 , and 6 by 3 , respectively.

\section{RESULTS AND DISCUSSION}

Table 1 presents the values of shoot weight ( $W s)$, leaf area $(L a)$ and water consumed (Eta) between harvests, at the indicated number of days after seedling emergence. In general, for the first five harvests, Río Piedras, Isabela, and Petit Bourg exhibit similar values in the weight of shoot and leaf area per plant. The values for water consump- 
TABLE 1. - Mean values per plant of the weight of shoot, leaf area, and water consumption between harvests by grain sorghum plants grown in pots at four experimental sites, taken on the indicated number of days after emergence

\begin{tabular}{|c|c|c|c|}
\hline Days after emergence & Weight of shoot & Leaf area & Water use \\
\hline & $G$ & $\mathrm{Cm}^{2}$ & $M l$ \\
\hline \multicolumn{4}{|c|}{ Río Piedras } \\
\hline 10 & 0.10 & 41 & 350 \\
\hline 17 & 1.26 & 258 & 465 \\
\hline 24 & 3.97 & 755 & 1135 \\
\hline 31 & 14.40 & 1890 & 2030 \\
\hline 38 & 29.27 & 2276 & 3845 \\
\hline 45 & 61.67 & 2333 & 3105 \\
\hline 52 & 69.64 & 3032 & 6385 \\
\hline \multicolumn{4}{|c|}{ Isabela } \\
\hline 13 & .13 & 45 & 540 \\
\hline 20 & .76 & 194 & 520 \\
\hline 27 & 3.85 & 585 & 895 \\
\hline 34 & 10.17 & 630 & 1755 \\
\hline 41 & 23.81 & 2169 & 3550 \\
\hline 48 & 40.41 & 2780 & 3525 \\
\hline 55 & 44.91 & 2067 & 2595 \\
\hline \multicolumn{4}{|c|}{ Petit Bourg } \\
\hline 13 & .15 & 53 & 625 \\
\hline 18 & .69 & 226 & 650 \\
\hline 25 & 3.17 & 566 & 990 \\
\hline 32 & 11.31 & 1457 & 1625 \\
\hline 39 & 26.77 & 2302 & 3065 \\
\hline 46 & 33.67 & 2734 & 3015 \\
\hline 53 & 39.10 & 2458 & 3410 \\
\hline \multicolumn{4}{|c|}{ Belle Glade } \\
\hline 10 & .02 & 6 & 70 \\
\hline 17 & .24 & 50 & 140 \\
\hline 24 & 1.39 & 231 & 355 \\
\hline 31 & 4.92 & 661 & 995 \\
\hline 38 & 11.20 & 957 & 1660 \\
\hline 45 & 15.60 & 1532 & 3105 \\
\hline 52 & 31.51 & 2372 & 2855 \\
\hline
\end{tabular}

tion between harvests also reveal some similarity. However, there is some difference in their sampling dates (days after emergence) that may increase or decrease similarity of data among sites. This effect will be covered in the exponential growth rate analysis.

On the other hand there is an approximate time lag of from 2 to $2^{1 / 2}$ harvests at Belle Glade when the weight of the shoot per plant at this site is compared with those at the other three sites. Yet, by the last 
harvest, the shoot weights at Belle Glade tend to approach the corresponding values from Isabela and Petit Bourg. In terms of leaf area, there is even greater similarity among sites at the final harvest, except for Río Piedras, which remained highest.

\section{Statistical Comparison of Shoot Weights}

The Ws data from each site (table 1) were subjected to statistical analysis of variance. Variations incident to plant age were highly significant at each site as shown in the following tabulation:

\begin{tabular}{lr}
\multicolumn{1}{c}{ Site } & F values \\
Río Piedras & $132.7^{* *}$ \\
Isabela & $21.7^{* *}$ \\
Petit Bourg & $53.6^{* *}$ \\
Belle Glade & $112.9^{* *}$
\end{tabular}

Belle Glade and Isabela exhibited the minimum and maximum variations, respectively. Similarly, weight variations with age were most consistent at Río Piedras and Belle Glade. In general, the harvest sequence data from Isabela and Petit Bourg contrast greatly with those from Belle Glade and Río Piedras.

Data were further evaluated with a different analytical design. Significant site-age variations were obtained for main effects and firstorder interactions (table 2).

\section{Weather vs. Growth and Water Consumption Rates}

Table 3 summarizes the mean values of the main weather components at each site for the periods between harvests. The solar radiation intensity $(R i)$ was generally greatest in Isabela and Petit Bourg, and lowest at Belle Glade, although for the final three weeks it closely simulated values from the other sites. Although the mean air tempera-

TABLE 2. - Analysis of variance for the weight of shoot (Ws) of grain sorghum, in which the effect of climatic sites and its interaction with harvests is under consideration

\begin{tabular}{lrrrr}
\hline Source of variation & d.f. & Sum of squares & Mean square & \multicolumn{1}{c}{$F^{1}$} \\
\hline Climatic sites & 3 & 3834.23 & 1278.07 & $4.83^{2}$ \\
Harvest age & 6 & 33836.18 & 5639.36 & $21.34^{3}$ \\
Sites $\times$ harvest age & 18 & 4756.08 & 264.22 & $9.08^{3}$ \\
Blocks & 12 & 397.29 & 33.10 & \\
Error & 72 & 2093.75 & 29.07 & \\
Total & 111 & 44917.53 & & \\
\hline
\end{tabular}

${ }^{1}$ The significance of main effects (sites and harvests) was measured against the mean square for sites $\times$ harvests, while for the latter interaction it was measured against the m.s. for the experimental error.

${ }^{2}$ Significant at the $5 \%$ level.

${ }^{3}$ Significant at the $1 \%$ level. 
TABLE 3. - Mean values of solar radiation (Ri), mean air temperature ( $T a)$, minimum $(T \mathrm{~mm})$ and maximum air temperature $(T m x)$, air saturation deficit $\left(e_{d}\right)$, wind speed $(u)$, dew point temperature $(T d)$, open pan evaporation $\left(E_{0}\right)$ and total rainfall $(P)$, as calculated for the weekly periods between harvests

\begin{tabular}{|c|c|c|c|c|c|c|c|c|c|}
\hline $\begin{array}{c}\text { Harvest } \\
\text { date } \\
1975\end{array}$ & $\begin{array}{c}\mathrm{Ri} \\
\mathrm{cal} / \mathrm{cm}^{2} / \\
\text { day }\end{array}$ & $\begin{array}{l}\mathrm{Ta} \\
{ }^{\circ} \mathrm{C}\end{array}$ & $\underset{{ }^{\circ} \mathrm{C}}{\mathrm{Tm} m}$ & ${ }_{{ }^{\circ} \mathrm{C}}^{\mathrm{Tm}} \mathrm{x}$ & $\begin{array}{r}e_{d} \\
m b\end{array}$ & $\begin{array}{c}\mathrm{u} \\
\mathrm{m} / \mathrm{sec}\end{array}$ & $\begin{array}{l}\mathrm{Td} \\
{ }^{\circ} \mathrm{C}\end{array}$ & $\underset{\mathrm{mm} / \text { day }}{\mathrm{E}_{\mathrm{o}}}$ & $\underset{\mathrm{mm}}{\mathrm{P}}$ \\
\hline \multicolumn{10}{|c|}{ Río Piedras } \\
\hline Mar. 7 & 441 & 24.3 & 18.8 & 29.8 & 4.04 & 0.34 & 21.9 & 3.88 & 16 \\
\hline 14 & 480 & 24.1 & 19.0 & 29.2 & 4.68 & .49 & 21.3 & 4.29 & 11 \\
\hline 21 & 512 & 23.6 & 18.5 & 28.7 & 5.21 & .47 & 20.4 & 4.85 & 15 \\
\hline 28 & 487 & 23.8 & 18.5 & 29.1 & 3.57 & .46 & 21.7 & 4.20 & 11 \\
\hline Apr. 4 & 490 & 23.7 & 18.4 & 29.0 & 5.01 & .38 & 20.6 & 4.24 & 32 \\
\hline 11 & 492 & 23.8 & 19.0 & 28.6 & 3.48 & .38 & 21.7 & 4.60 & 7 \\
\hline 18 & 551 & 24.6 & 18.9 & 30.4 & 5.57 & .39 & 21.3 & 5.31 & 7 \\
\hline \multicolumn{10}{|c|}{ Isabela } \\
\hline Mar. 10 & 574 & 23.0 & 18.2 & 27.9 & 5.79 & 1.15 & 19.2 & 4.67 & 20 \\
\hline 17 & 522 & 23.3 & 18.9 & 27.8 & 5.72 & 2.25 & 19.7 & 6.24 & 3 \\
\hline 24 & 500 & 22.7 & 17.0 & 28.5 & 5.93 & 1.24 & 18.8 & 5.44 & 0 \\
\hline 31 & 515 & 23.9 & 19.5 & 28.3 & 3.50 & 1.85 & 21.8 & 5.88 & 29 \\
\hline Apr. 7 & 510 & 23.5 & 18.5 & 28.6 & 5.07 & 1.28 & 20.3 & 6.20 & 0 \\
\hline 14 & 452 & 23.8 & 18.8 & 28.9 & 4.42 & 1.53 & 21.1 & 5.19 & 7 \\
\hline 21 & 572 & 24.2 & 19.0 & 29.4 & 12.05 & 1.99 & 16.0 & 6.57 & 7 \\
\hline
\end{tabular}

Petit Bourg

\begin{tabular}{|c|c|c|c|c|c|c|c|c|}
\hline Mar. 11 & 421 & 22.4 & 19.0 & 25.9 & 2.37 & 2.02 & 20.9 & 3.78 \\
\hline 16 & 393 & 22.1 & 18.4 & 25.9 & 3.51 & 2.06 & 19.8 & 4.30 \\
\hline 23 & 549 & 22.9 & 19.1 & 26.8 & 4.40 & 2.00 & 20.1 & 5.65 \\
\hline 30 & 550 & 23.2 & 19.5 & 26.9 & 3.57 & 2.07 & 21.0 & 6.03 \\
\hline pr. 6 & 559 & 22.7 & 18.5 & 27.0 & 4.06 & 1.94 & 20.1 & 5.30 \\
\hline 13 & 551 & 23.8 & 19.7 & 27.9 & 4.91 & 2.86 & 20.8 & 6.61 \\
\hline 20 & 565 & 24.1 & 20.5 & 27.8 & 6.05 & 3.29 & 20.4 & 6.53 \\
\hline
\end{tabular}

Belle Glade

\begin{tabular}{|c|c|c|c|c|c|c|c|c|c|}
\hline Mar. 10 & 440 & 17.1 & 9.9 & 24.4 & 8.09 & 1.52 & 8.9 & 3.81 & 10 \\
\hline 17 & 417 & 23.1 & 16.9 & 29.4 & 9.26 & 1.84 & 16.7 & 4.06 & 0 \\
\hline 24 & 469 & 20.9 & 13.0 & 28.9 & 8.42 & 1.68 & 14.3 & 4.06 & 1 \\
\hline 31 & 422 & 23.8 & 17.4 & 30.2 & 10.10 & 1.84 & 17.0 & 3.92 & 0 \\
\hline Apr. 7 & 547 & 21.7 & 15.3 & 28.1 & 10.98 & 1.63 & 13.0 & 5.30 & 0 \\
\hline 14 & 437 & 19.3 & 13.0 & 25.6 & 2.64 & 1.81 & 17.3 & 3.92 & 28 \\
\hline 21 & 535 & 22.8 & 16.4 & 29.3 & 8.99 & 2.00 & 16.5 & 7.49 & 0 \\
\hline
\end{tabular}

ture ( $T a$ ) was quite similar among sites, at Belle Glade the minimum air temperature was significantly lower in most of the periods between harvests.

With reference to humidity there was a marked difference in the air saturation deficit $\left(e_{d}\right)$ between Belle Glade and the other sites. Yet, Isabela exhibited the highest saturation deficit among all sites in the 
week before its last harvest. Even the dew point temperature $(T d)$ points to a drier air condition at the latter site, considering the cooler air at Belle Glade during the respective week before the final harvest.

The dew-point temperature at Belle Glade and Petit Bourg was directly and continuously recorded (by dew-cell method), while at Río Piedras and Isabela it was indirectly calculated from a continuous tracing of the relative humidity (R.H.). Therefore, the air saturation deficit $\left(e_{d}\right)$ was also calculated differently ${ }^{4}$ at Río Piedras and Isabela from that of Belle Glade and Guadeloupe. An attempt was made to determine whether the dew-point and the saturation deficit thus obtained at the four sites represent comparable values for air humidity, in spite of the different techniques and approaches used to arrive at

TABLE 4.-Correlation coefficients of some of the growth and water consumption rate parameters as a function of different weather factors and of a biological growth factor calculated from data of four sites

\begin{tabular}{lccc}
\hline & $\begin{array}{c}\mathrm{k}_{\mathrm{ks}} \\
(\mathrm{RGR})\end{array}$ & $\begin{array}{c}\text { Plant parameters } \\
\mathrm{k}_{\mathrm{ls}} \\
(\mathrm{ULR})\end{array}$ & $\begin{array}{c}\mathrm{k}_{\mathrm{es}} \\
(\text { WUR })\end{array}$ \\
\hline Solar radiation $(\mathrm{Ri})$ & $r$ & $r$ & $r$ \\
Air temperature $(\mathrm{Ta})$ & $-.513^{1 *}$ & $-.590^{2 * *}$ & $-.599^{* *}$ \\
Saturation deficit $\left(\mathrm{e}_{\mathrm{d}}\right)$ & -.138 & -.080 & -.257 \\
Wind speed $(\mathrm{u})$ & -.042 & -.060 & -.119 \\
Pan evaporation $(\mathrm{Eo})$ & -.145 & -.165 & -.233 \\
Growth factor $\left(\frac{1}{\mathrm{x}}\right)$ & $-.442^{*}$ & -.348 & $-.417^{*}$ \\
& $.954^{* *}$ & $.464^{*}$ & $.901^{* *}$ \\
\hline
\end{tabular}

${ }^{1}$ Significant at the $5 \%$ level.

2 Significant at the $1 \%$ level.

such values. It was found that when comparing $e_{d}$ vs. $T a-T d$, a common and highly-significant straight-line relationship was obtained.

The possible influence of the weather factors on the rate of shoot growth and of water use was investigated by simple linear regression. The exponential growth rate indices RGR, ULR, and WUR, derived from equations 1,2 , and 5 , as described in the procedure, were chosen as the better related weather-dependent plant indices. A biological growth factor was also included in the regression analysis. It was taken as $1 / x$, the value of the slope in the functional relation $x=\mathrm{f}\left(e^{x}\right)$, where $e^{x}$ represents a mid-period day number, which ranges from 13.5 to 51.5. This function traces an approximate grand-growth curve. Therefore, $1 / x$ serves as a biological index, with respect to which the relative contribution to growth of weather indices may be evaluated.

Table 4 presents the correlation coefficients $(r)$ obtained for some growth- and water-consumption rate indices as a function of weather

${ }^{4}$ At Río Piedras and Isabela $e_{d}$ was calculated from the equation: $e_{d}=e_{s}-\mathrm{e}_{s}$ (R.H.), where $\mathrm{e}_{8}$ is the saturated vapor pressure at $T a$, obtained from tables. At Belle Glade and Petit Bourg $e_{d}=e_{s}($ at $T a)-e_{s}($ at $T d)$. 
factors and the biological growth factor $(1 / x)$. Only solar radiation intensity $(R i)$ and pan evaporation $(E O)$ appeared to affect RGR, ULR, and WUR. The individual influence of the mean air temperature $(T a)$ and of the aerodynamic variables $\left(e_{d}\right.$ and $u$ ) were negligible. On the other hand, the high correlation between the mean daily growth rates $\left(k_{s s}\right)$ with the biological growth factor suggests that the plants maintained similar grand periods of growth at each site.

Yet, the correlations of growth/unit leaf area (ULR) with solar energy were statistically more significant than that for ULR vs. $1 / x$. ULR remained fairly constant during the 52-day interval (table 5).

TABLE 5. - Mean slopes of relative growth rate $\left(k_{s s}\right)$, unit leaf rate $\left(k_{s l}\right)$, relative leaf growth rate $\left(k_{l}\right)$, leaf growth rate $\left(k_{l s}\right)$, water use rate $\left(k_{e s}\right)$, and relative transpiration efficiency $\left(k_{e V}\right)$, obtained from the exponential growth rate equation on the indicated days after germination of the grain sorghum

\begin{tabular}{|c|c|c|c|c|c|c|}
\hline $\begin{array}{c}\text { Days } \\
\text { following } \\
\text { emergence (ta) }\end{array}$ & $\begin{array}{c}k_{65} \\
\text { (RGR) }\end{array}$ & $\begin{array}{c}\mathrm{k}_{\mathrm{sl}} \\
\text { (ULR) }\end{array}$ & $\stackrel{\mathrm{k}_{11}}{(\mathrm{RLGR})}$ & $\begin{array}{c}\mathrm{k}_{\mathrm{ks}} \\
(\mathrm{LGR})\end{array}$ & $\begin{array}{c}\mathbf{k}_{\mathrm{es}} \\
\text { (WUR) }\end{array}$ & $\underset{(\mathrm{RTR})}{\mathbf{k}_{\mathrm{el}}}$ \\
\hline \multicolumn{7}{|c|}{ Río Piedras } \\
\hline 17 & .3591 & .8183 & .2628 & 1.1194 & 1.2035 & .3469 \\
\hline 24 & .1640 & .7195 & .1534 & .9137 & .9719 & .2116 \\
\hline 31 & .1835 & .7501 & .1311 & .8808 & .8910 & .1413 \\
\hline 38 & .1013 & .7204 & .0265 & .7233 & .7982 & .1015 \\
\hline 45 & .1065 & .8003 & .0035 & .6255 & .6663 & .0444 \\
\hline 52 & .0173 & .8141 & .0374 & .5565 & .6628 & .1438 \\
\hline \multicolumn{7}{|c|}{ Isabela } \\
\hline 20 & .2501 & .7328 & .2087 & 1.0418 & 1.1827 & .3496 \\
\hline 27 & .2318 & .7558 & .1577 & .9494 & 1.0102 & .2184 \\
\hline 34 & .1388 & .7369 & .0106 & .7282 & .8746 & .1302 \\
\hline 41 & .1215 & .8478 & .1766 & .7661 & .8365 & .2470 \\
\hline 48 & .0756 & .7468 & .0355 & .6800 & .7139 & .0694 \\
\hline 55 & .0150 & .7264 & .0423 & .5621 & .5946 & .0098 \\
\hline \multicolumn{7}{|c|}{ Petit Bourg } \\
\hline 18 & .3052 & .9738 & .2900 & 1.4635 & 1.6748 & .5013 \\
\hline 25 & .2178 & .7062 & .1312 & .9585 & 1.0384 & .2110 \\
\hline 32 & .1817 & .7568 & .1351 & .8758 & .8914 & .1507 \\
\hline 39 & .1231 & .7448 & .0653 & .7594 & .8003 & .1062 \\
\hline 46 & .0328 & .7122 & .0246 & .6609 & .6749 & .0385 \\
\hline 53 & .0214 & .7090 & .152 & .6129 & .6597 & .0316 \\
\hline \multicolumn{7}{|c|}{ Belle Glade } \\
\hline 17 & .3231 & .8559 & .3029 & 1.0858 & 1.2329 & .4500 \\
\hline 24 & .2509 & .8040 & .2186 & .9814 & 1.0428 & .2800 \\
\hline 31 & .1806 & .7659 & .1502 & .8806 & .9391 & .2086 \\
\hline 38 & .1125 & .7332 & .0529 & .7529 & .8316 & .1315 \\
\hline 45 & .0473 & .7277 & .0672 & .7026 & .8036 & .1681 \\
\hline 52 & .1004 & .7609 & .0625 & .7177 & .7442 & .0265 \\
\hline
\end{tabular}


Thus, there is a greater dependence of this plant growth index on sunlight than on other environmental factors, location, or plant growth characteristics. The overall decreasing character of the slopes of the plant growth indices makes the correlations inverse, except when compared to $1 / x$, whose slopes also have a decreasing character.

Similarly to RGR, the mean daily rate of water use per unit of shoot weight, WUR $\left(k_{e s}\right)$, correlates more closely with Ri, and less so with $E_{o}$, than the other climatic variables. Here we have an example of how plant-water-weather interrelationships can be visualized working together.

The rate of water consumption/unit weight decreases with time. This rate of decrease can be reasonably predicted, considering that $r=.90$ for the regression of WUR vs. $1 / x$; though it is also suggested that solar radiation intensity plays a role too. No improvement in the prediction of RGR, ULR, or WUR was obtained when more than one weather variable was included in a multiple regression with or without the biological growth factor added to the analysis.

Yet, the integrated role of weather on plant growth is best exemplified by the amount of its water use, relative to other places and time. As Paltridge and De Vries (7) suggest, the total water transpired may be considered an effective summation of the weather effects. When plant weight by harvest was compared with water consumption, the latter measure accounted for $92.8 \%$ of shoot-weight variability. Moreover, it was found that when the values of water-use rate $\left(k_{e s}\right)$ were compared to those of the leaf-growth rate $\left(k_{l s}\right)$, water consumption accounted for $97.3 \%$ of growth-rate variability. The somewhat better correlation of water-use rate vs. leaf-growth rate may be attributed to the fact that the water consumed under the present conditions was mainly transpired. The water lost from potted soil alone was roughly from 10 to $20 \%$ of that in potted plants.

\section{The Exponential Growth and Water Use Rate Analysis}

In order to evaluate their similarity among sites, the mean daily growth and water-consumption rate indices summarized in table 5 were object of linear regression as a function of the days following seedling emergence $(t a)$. The weekly rates $(\ln A / B)$ were also analyzed similarly.

Table 6 summarizes the statistical data obtained for the $\mathrm{k}$ values presented in table 5, when compared with the days after germination of the grain sorghum. It is apparent that those indices related with the mean daily rates of increase in leaf area (LGR), in water use (WUR), and in shoot weight (RGR); all with respect to their shoot weight (Ws) at $t=o$, experienced common or similar fluctuations with time among 
the four climatic sites. Leaf area, as an initial value at $t=0$, gave way to dissimilar rates of increase in shoot weight $\left(k_{s l}\right)$ and in leaf area $\left(k_{l l}\right)$. The unit leaf rate $\left(k_{s \nu}\right)$ was very poorly related to days after seedling emergence, which is in agreement with its lack of good correlation with $1 / x$ (B.G.F.). Correlations of weekly rates (ln $A / B$ ) with $t_{a}$ equalled or exceeded expectations. A slight improvement in the correlation coefficient values was obtained when $t_{a}$ was taken as the mid-week day, rather than the final day. But, again, with respect to $\mathrm{ULR}$, the regression did not correlate as well as $k_{s l}$ vs. $t_{\alpha}$. Thus, so far ULR is better related to Ri than to any other variable.

A second degree polynomial was found to fit better the relationships

TABLE 6. - Statistical data obtained when the mean daily ( $k$ ) and weekly ( $\sum k$ ) growth and water consumption rate parameters were used in linear regression, all four sites included in each analysis

\begin{tabular}{|c|c|c|c|c|}
\hline $\begin{array}{l}\text { Regression varia- } \\
\text { bles }\end{array}$ & $\begin{array}{l}\text { Correlation } \\
\text { coefficient }\end{array}$ & Intercept & $\begin{array}{l}\text { Regression } \\
\text { coefficient }\end{array}$ & Means \\
\hline \multicolumn{5}{|l|}{$R G R:$} \\
\hline $\mathrm{k}_{\mathrm{ss}}$ vs ta & .946 & 0.423 & -0.008 & 0.153 \\
\hline$\sum \mathrm{k}_{\mathrm{ss}} \mathrm{vs}$ ta & .932 & 2.823 & -.050 & 1.044 \\
\hline \multicolumn{5}{|l|}{ ULR: } \\
\hline $\mathrm{k}_{\mathrm{si}} \mathrm{vs}$ ta & .376 & .834 & -.002 & .769 \\
\hline$\sum_{L G R:}^{\sum k_{s 1} \text { vs ta }}$ & .130 & 5.409 & -.003 & 5.291 \\
\hline $\mathrm{k}_{\mathrm{ls}}$ vs ta & .897 & 1.587 & -.015 & 1.042 \\
\hline$\sum \mathrm{k}_{\mathrm{ls}}$ vs ta & .963 & 9.002 & -.093 & 5.711 \\
\hline \multicolumn{5}{|l|}{ WUR: } \\
\hline $\mathrm{k}_{\mathrm{es}} \mathrm{vs}$ ta & .880 & 1.523 & -.017 & .906 \\
\hline$\sum \mathrm{k}_{\mathrm{ls}}$ vs ta & .964 & 9.919 & -.105 & 6.201 \\
\hline \multicolumn{5}{|l|}{ RLGR: } \\
\hline $\mathrm{k}_{11}$ vs ta & .729 & .363 & -.007 & .115 \\
\hline$\sum \mathrm{k}_{11} \mathrm{vs}$ ta & .870 & 2.379 & -.046 & .748 \\
\hline \multicolumn{5}{|l|}{$R T R:$} \\
\hline $\mathrm{k}_{\mathrm{el}} \mathrm{vs}$ ta & .860 & .509 & -.009 & .180 \\
\hline$\sum \mathrm{k}_{\mathrm{el}} \mathrm{vs}$ ta & .877 & 3.346 & -.059 & 1.212 \\
\hline
\end{tabular}

between the weekly rates of LRG $\left(\ln \frac{\mathrm{LA}_{1}}{\mathrm{Ws}_{0}}\right)$ vs. days after germination (ta), and of the weekly rates of WUR $\ln \frac{\mathrm{Eta}_{1}}{\mathrm{Ws}_{0}}$ vs. ta too (fig. 2 and 3). In both cases the contribution of the quadratic term was significant at the 5 and $1 \%$ levels. As noted earlier, relative to the highly significant correlation between $k_{l s}$ vs. $k_{e s}$, the leaf-water-shoot interrelationships remain unique and consistent with time, and among the four sites.

A further step was taken to verify whether the climatic sites exerted any significant influence on the mean daily $k$ values when the effect of 
time (age) was deleted, so that harvest-sequence values could be taken as replicates. Table 7 presents an analysis of variance of discrete growth and water consumption rate indices as influenced by site. $F$ values for sites indicate that no significant site effects were exerted on the six plant indices. A significance test for the means of sites also indicates that none of the individual treatment (sites) means, for any

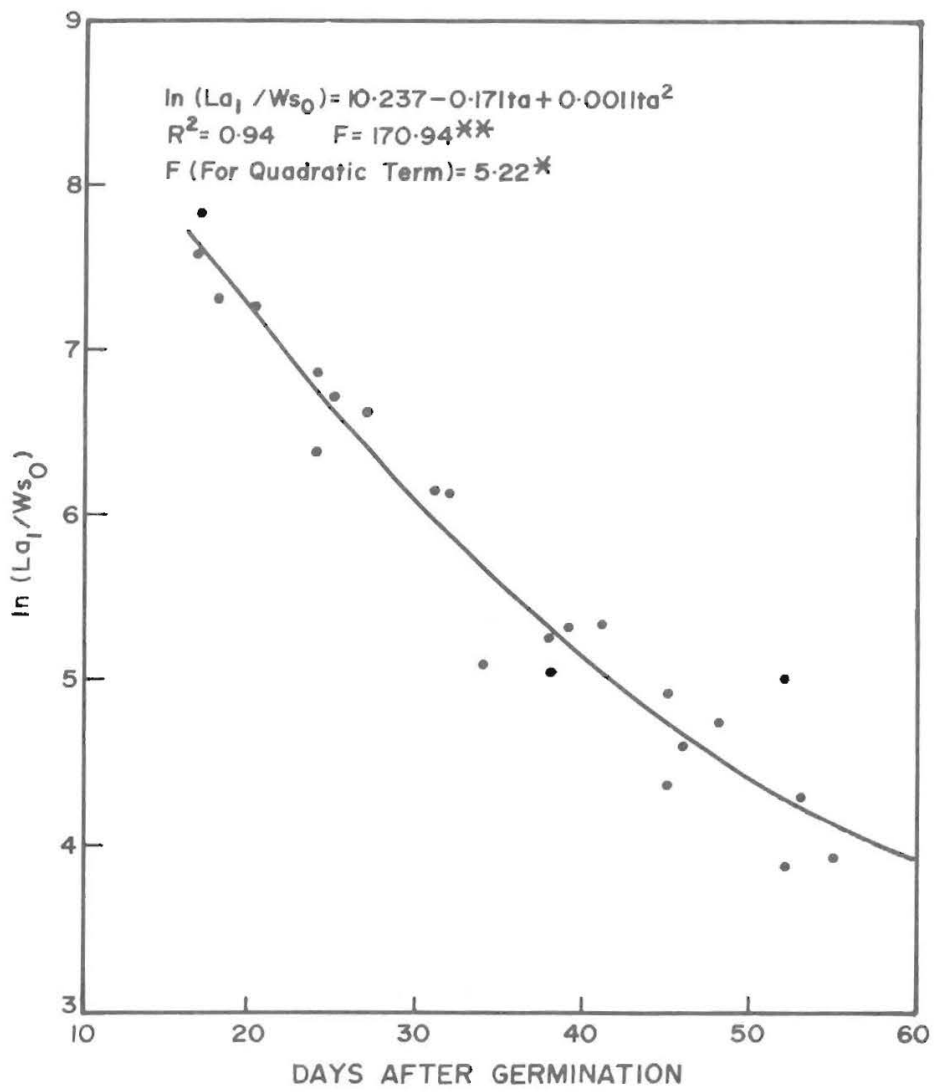

FIG. 2. - Quadratic relationship of the $\ln \left(\mathrm{La}_{1} / \mathrm{Ws}_{0}\right)$ as a function of the number of days after germination (ta) of grain sorghum in pots, including the four climatic sites.

one of the six k groups, was significantly exceeded by any other site mean.

\section{Final Remarks}

Climatic sites appear to have exerted a significant effect on total yields $\left(W_{s}\right)$. A highly-significant interaction was obtained for sites $\times$ harvest age. As expected, the single effect of harvest age on shoot weight was also highly significant. 


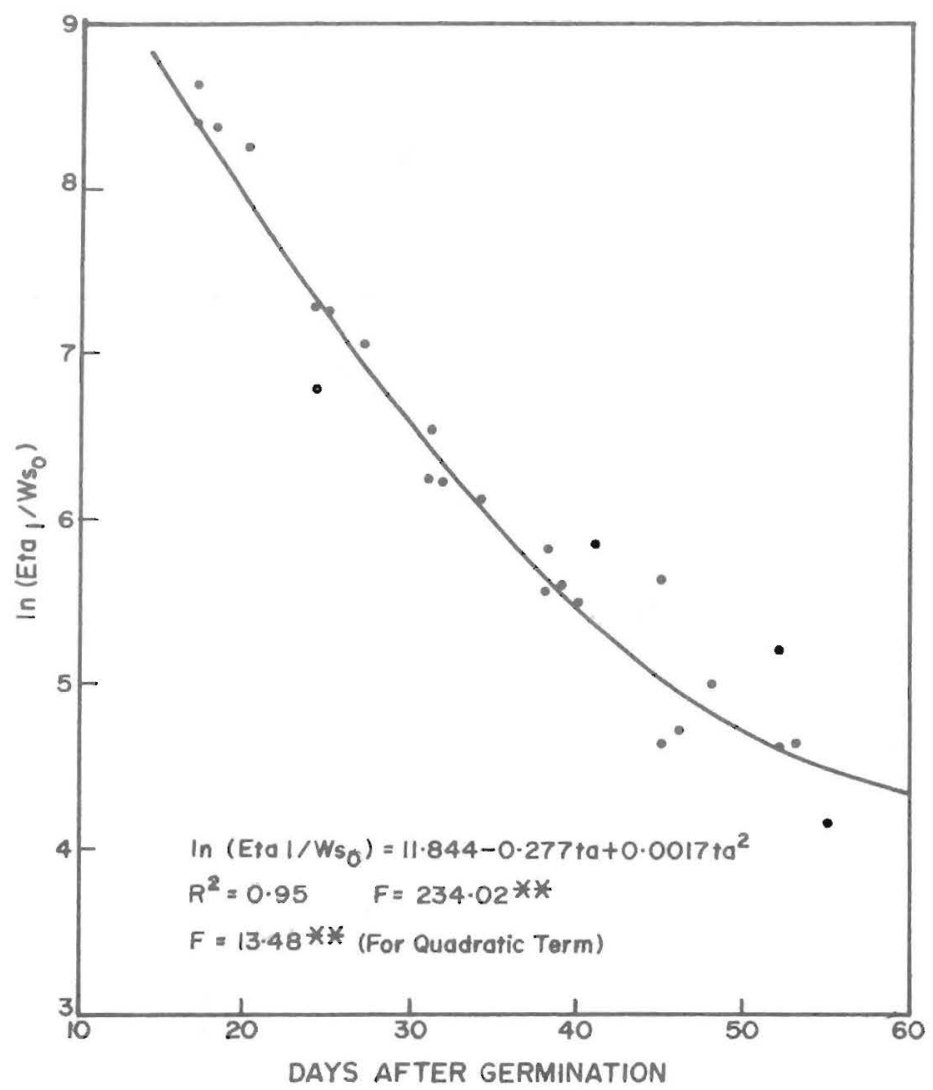

Frg. 3.-Quadratic relationship of the $\ln \left(\mathrm{Eta}_{1} / \mathrm{Ws}_{0}\right)$ as a function of the number of days after germination (ta) of grain sorghum in pots, including the four climatic sites.

TABLE 7. - Analysis of variance of the various mean daily rates of growth and water use rates as influenced by sites

\begin{tabular}{|c|c|c|c|c|c|c|c|}
\hline $\begin{array}{l}\text { Source of } \\
\text { variation }\end{array}$ & d.f. & $\begin{array}{c}\mathrm{RGR} \\
\mathrm{k}_{\mathrm{es}}\end{array}$ & $\begin{array}{c}\text { ULR } \\
\mathrm{k}_{\mathrm{sl}}\end{array}$ & $\begin{array}{c}\text { RLGR } \\
\mathrm{k}_{11}\end{array}$ & $\begin{array}{c}\mathrm{LGR} \\
\mathrm{k}_{\mathrm{ls}}\end{array}$ & $\begin{array}{c}\text { WUR } \\
\mathbf{k}_{\text {es }}\end{array}$ & $\begin{array}{c}\text { RTR } \\
\mathrm{k}_{\mathrm{el}}\end{array}$ \\
\hline Sites & 3 & & & & & & \\
\hline S.s & & 0.0031 & 0.0009 & 0.0065 & 0.0385 & 0.0376 & 0.0082 \\
\hline $\mathrm{m} . \mathrm{s}$ & & .0010 & .0003 & .0021 & .0128 & .0125 & .0027 \\
\hline$F$ & & $.92 \mathrm{Ns}^{1}$ & $.08 \mathrm{Ns}$ & $.96 \mathrm{Ns}$ & $1.69 \mathrm{Ns}$ & $1.19 \mathrm{Ns}$ & $.75 \mathrm{Ns}$ \\
\hline Replicates & 5 & & & & & & \\
\hline S.s. & & .2035 & .0295 & .1612 & .8628 & 1.1556 & .3413 \\
\hline Error & 15 & & & & & & \\
\hline s.s & & .0171 & .0563 & .0339 & .1139 & .1580 & .0543 \\
\hline Total & 23 & & & & & & \\
\hline S.S & & .2239 & .0868 & .2017 & 1.0152 & 1.3513 & .4039 \\
\hline
\end{tabular}

${ }^{1}$ Not significant. 
The absolute yield differences are intimately related with differences in water consumption, the latter accounting for $92.8 \%$ of the fluctuations in weight of shoot. These plant-water interrelations are even more revealing when comparing the leaf growth rate with the water consumption rate itself $(r=.986)$. Also, the solar energy control over these relationships is evident, if we note that it influenced especially the unit-leaf rate and the water-consumption rate, irrespective of site (table 4).

Yet, the fact that the daily growth and water consumption rates maintained uniform trends with time among the four sites, as reflected in tables 6 and 7, should not be surprising. There was a high degree of interaction between RGR and LGR with WUR, with the points of all four climatic sites intermixing along the regression lines. ULR was not related to any of the studied $k^{15}$. It was most intimately related to solar radiation (Ri), just as WUR. Every crop is likely to be attributed to its own intrinsic rate characteristic. ULR may define it.

Inasmuch as soil moisture availability was continuously favorable for equally old sorghum plants grown from the same seed batch, growing on the same and equally treated potted soil until seeding, only climatic variables could be held responsible for the differential weight response (Ws) of plants on any one sampling day (tables 1 and 2). Yet, only solar radiation intensity as an independent climatic index, could be identified with the interrelationships between growth and waterconsumption rates with the environment. Pan evaporation, because of its energy integrating role, was less directly related to RGR and WUR.

Thus, dry-matter accumulation or net assimilation is governed by rate processes which in this study are examplified by water uptake (WUR) and cell growth (RGR and ULR). Within the warmer tropics and subtropics ULR remains fairly constant, but still, its slight fluctuations are more related to solar radiation intensity than to any of the examined independent variables, including days after seedling emergence.

Other aspects of this study, including an evaluation of the leaf area ratio (LAR), water use efficiency (WUE), and leaf transpiration efficiency (LTE), will be covered in a future paper. Additional features, such as nutrient uptake, root growth, and root-shoot ratio will also be reported in a later paper.

\section{RESUMEN}

Se realizó un estudio ecológico para evaluar la producción de materia seca y la tasa exponencial de crecimiento y de uso de agua por el sorgo (Sorghum bicolar) en tres regiones tropicales y una subtropical. El estudio se realizó en tiestos regados por capilaridad mediante una técnica diseñada expresamente para medir el agua utilizada por el sorgo. A partir del décimo día después de la germinación se efectuaron siete 
cosechas semanales de la parte aérea y de las raíces, separadamente, para así determinar el peso seco por planta así como el área foliar.

Tomando como base el peso de la materia seca del tallo, el análisis de varianza revela una respuesta significativa del peso de la planta al efecto producido por el clima de cada región, así como una interacción entre esta variable y la edad de la planta. En términos de tasa exponencial de crecimiento y uso de agua, los indices calculados al efecto observaron un patrón común en razón de los climas de cada región. Se encontró una aparente influencia de la radiación solar en algunos de estos indices.

\section{LITERATURE CITED}

1. Baier, W., 1973. Crop-weather analysis model: Review and model development, J. Appl. Meteor. 12(6): 937-47.

2. Beinroth, F. H., March 1973. Crop production and land potential of benchmark soils of Latin America. A research proposal submitted to AID. College of Agricultural Sciences, U.P.R., Mayagüez Campus.

3. Capiel, M., 1978. Effect of various meteorological indices on the yield and nutrient composition of Napiergrass. J. Agric. Univ. P.R. 62(1): 76-89.

4. - 1973. A differential psychro test of plant-soil-weather relationships and water use, J. Agric. Univ. P.R. 57(1): 42-55.

5. Clifford Evans, G., 1972. The Quantitative Analysis of Plant Growth, Univ. Calif. Press, Berkeley and Los Angeles, Calif., 587 pp.

6. Jacques, G. L., Vanderlip, R. L., and Whitney, D. A. 1975. Growth and nutrient accumulation and distribution in grain sorghum. I. Dry matter production and Ca and Mg. uptake and distribution, Agron. J. 67(5): 607-11.

7. Paltridge, T. B., and De Vries, M. P. C., 1973. Grain yields in wheat per unit area and per unit of silicon as a measure of water transpired, Aust. J. Agric. Res. 24: $633-45$. 